Rakenteiden Mekaniikka (Journal of Structural Mechanics)

Vol. 50, No 3, 2017, pp. 368-371

https://rakenteidenmekaniikka.journal.fi/index

https:/doi.org/10.23998/rm.64936

(c)Author(s) 2017.

Open access under CC BY-SA 4.0 license.

\title{
Topology optimization of cast iron parts
}

Timo Turkkila

Summary. This article presents experiences of topology optimization. In the example, commercial software is used to find the optimal topology of the cast iron part.

Key words: structural optimization, topology optimization

Received 16 June 2017. Accepted 21 August 2017. Published online 21 August 2017.

\section{Topology optimization}

The basic idea of topology optimization is quite simple: a user defines a maximum structure or a space reservation, loadings and boundary conditions of the structure, and the optimization problem. After that, an optimization software removes all extra material. The same idea can be applied for trusses, frames, solid parts and any other applications. Nowadays one popular application of the topology optimization is 3D printing where the topology optimization is needed to find the full potential of the structure. However, the topology optimization can be also applied for the traditional manufacturing methods, like casting.

Topology optimization can typically be described as a discrete optimization problem where a binary variable specifies the existence of material. Finding an exact solution for a discrete optimization problem is time consuming. In the topology optimization of solid parts, each element has its own topology design variable so there can be thousands or even millions of binary type design variables. This kind of optimization problem cannot normally be solved with any discrete optimization algorithm. One commonly used idea is to relax binary variables to continuous ones by using virtual density variables. Variable value 0 represents void and 1 full material. Penalty terms are applied to avoid intermediate values. Unfortunately, this method does not work perfectly, thus some post processing is needed and the user or the optimization algorithm must select a limit value for the density variable. If density variable value is below this selected limit the material point is removed. 
Topology optimization modules are available in many FEM and CAD software. Usually CAD software are easier to use but FEM software have more options to define loads boundary conditions and optimization problem. Our company, Dtream Oy, is using Altair's software package. More information about topology optimization and our software can be found for example in Bendsoe's book [1], web pages of universities (e.g. [2]) and software documentations (e.g. [3]).

\section{Cast iron optimization example}

Example part is a simple bedplate presented in Figure 1. The material is cast iron ASTM class 30 [4] $\left(E=100 \mathrm{GPa}, v=0.29, \rho=7150 \mathrm{~kg} / \mathrm{m}^{3}\right)$. This material has yield limit 752 $\mathrm{MPa}$ for compression and $214 \mathrm{MPa}$ for tension. Safety factor is 3 so the maximum stress is $250 \mathrm{MPa}$ for compression and $71 \mathrm{MPa}$ for tension. These limits can be slightly violated in the small areas, especially around the bolts.

The bedplate has been fixed with four M12 bolts and there should be open space to tighten these bolts. In the finite element model, the bolts are replaced with rigid elements. The contact between the bedplate and the wall has been created by using so called fast contact of our Altair's Optistruct software. It can handle a simple contact without friction in the linear FEM analysis. The constant loading is pressure $500 \mathrm{kPa}$ for $150 \mathrm{x} 250 \mathrm{~mm}$ area as shown in Figure 1.
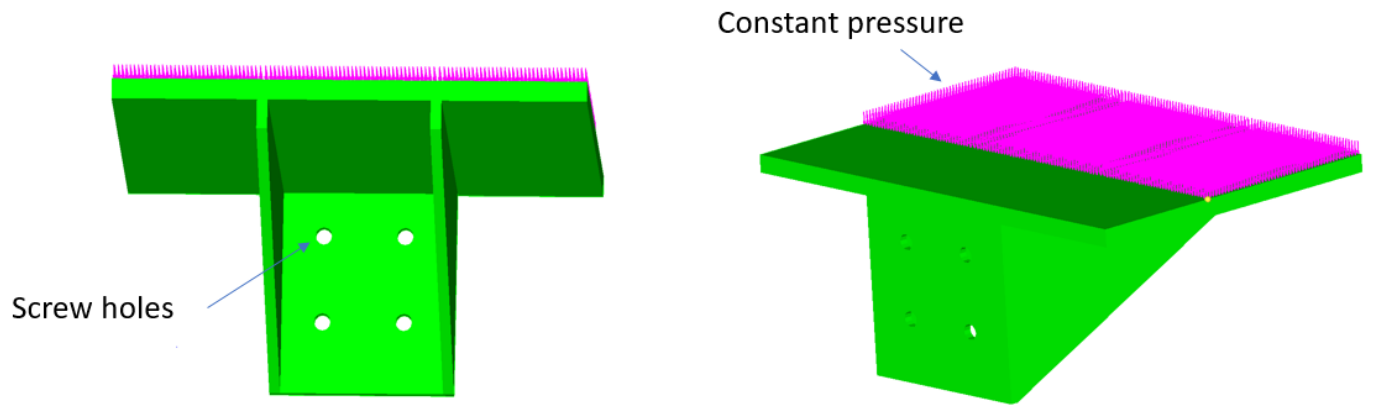

Figure 1 Original design of bedplate and its loadings

The mass of the original structure is $12.1 \mathrm{~kg}$, the maximum tension stress value is 83 $\mathrm{MPa}$ close to the bolts and $65 \mathrm{MPa}$ small area in the deck, the maximum compression stress value $101 \mathrm{MPa}$ and the maximum displacement value $1.14 \mathrm{~mm}$.

The optimization problem is to minimize mass and to maximize stiffness so that the stress constraints are not violated and the part is manufactured by casting. The mass reduction is more important target than the stiffness increase.

The first step of the optimization is to define a space reservation. In this case, it is 250x350x157 mm solid. It has been divided into two parts. A fixed part shall be full material all the time. The rest of the solid is a free part where optimization can remove 
material. Only half of the part is modelled and the contact between the rigid wall and the part is also applied during the topology optimization process. The space reservation model is presented in Figure 2

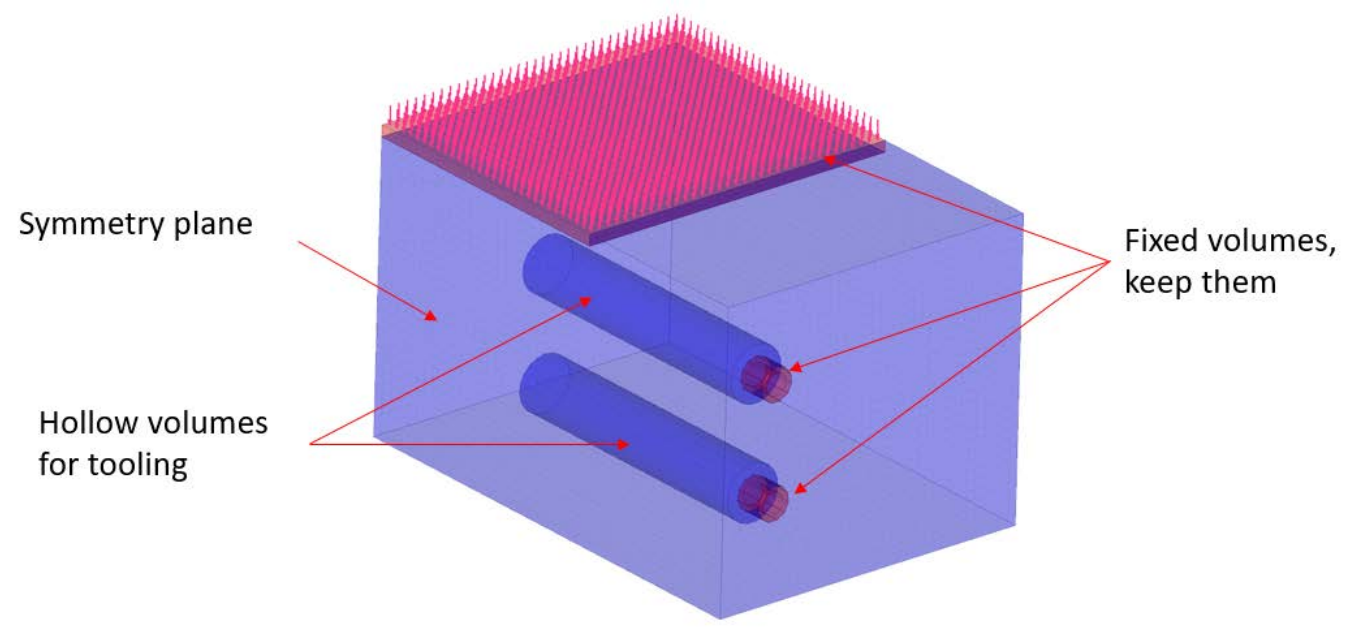

Figure 2. Space reservation model for topology optimization

Topology optimization is done with a traditional optimization problem: minimizing compliance with the mass constraint. The opening direction of the mould is defined with the draw direction constraint. Stress constraint is a bit problematic since in Optistruct only von Mises stress can be used in the topology optimization but, in this example, there are different stress limits for tension and compression. This constraint is removed from the topology optimization but it is applied in the later iterations where the final shape of the structure is defined. A few mass values have been tested and the most promising topology optimization result is presented in Figure 3. The default optimization method of the software is MFD (Methods of Feasible direction).

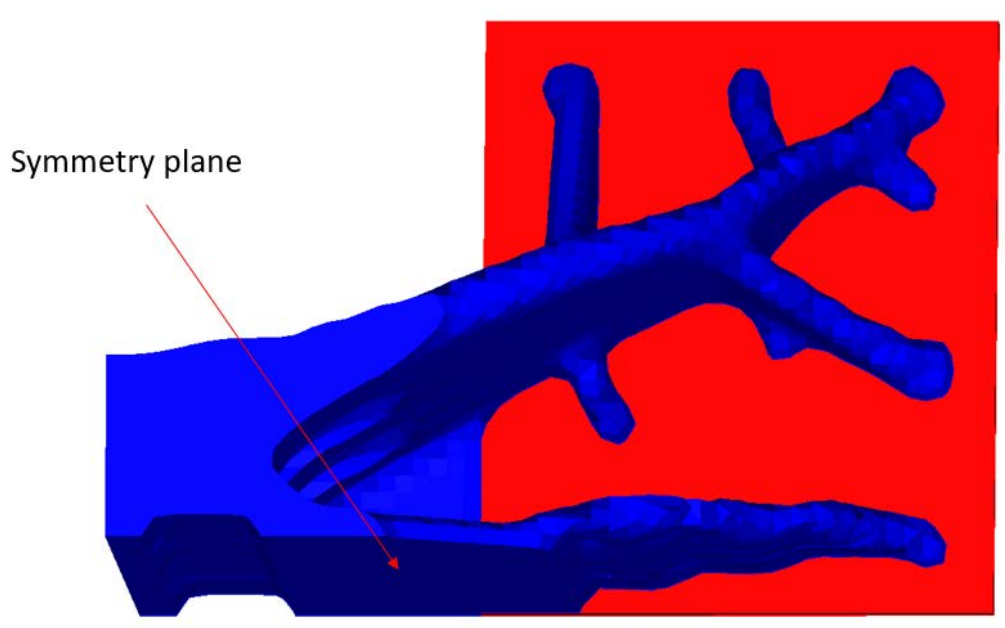

Figure 3. Optimal topology 
The optimal topology looks interesting but it is not ready to cast. It gives a good idea but nothing more. A few iteration loops are needed to get light and manufactural structure. The final structure is presented in Figure 4. The mass of this part is $8.6 \mathrm{~kg}$ and the maximum displacement is $0.79 \mathrm{~mm}$. The maximum tension stress value is approximately $70 \mathrm{MPa}$ and the maximum compression stress value is about $200 \mathrm{MPa}$. The final mass saving in about $30 \%$ and at the same time the optimized structure is over $40 \%$ stiffer.

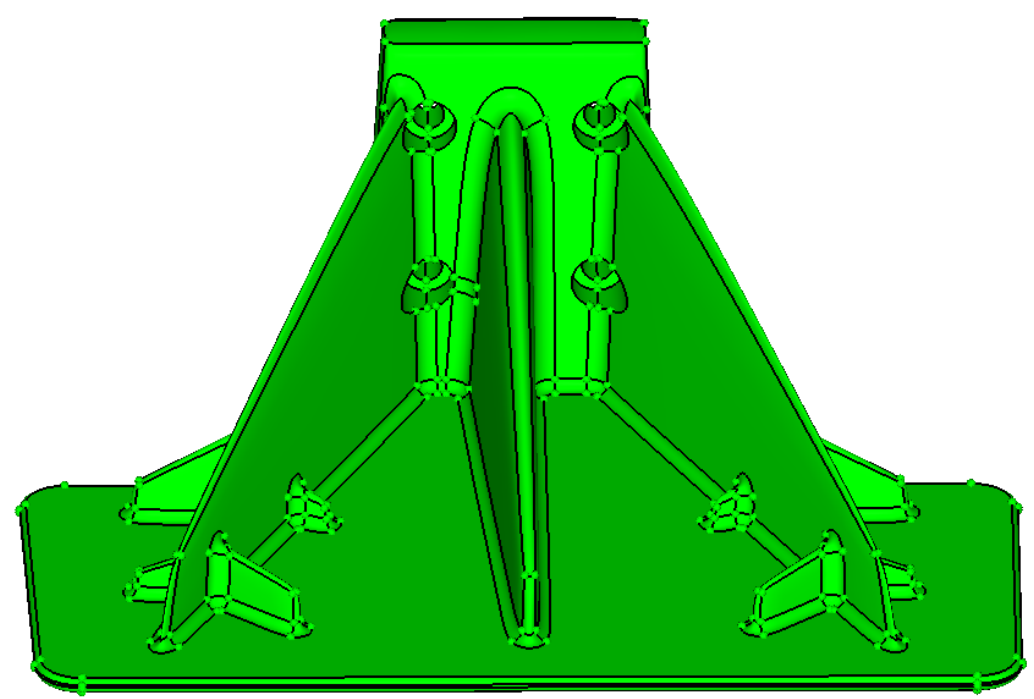

Figure 4. Final structure

\section{References}

[1] Bendsoe, M.P., Sigmund, O. Topology Optimization - Theory, Methods and Applications. Springler-Verlag, Berlin Heidelberg, 2003

[2] TopOpt research group (DTU), http://www.topopt.dtu.dk/, 15.6.2017

[3] Altair University, http://www.altairuniversity.com/learning-library/, 15.6.2017

[4] Matweb, www.matweb.com, 15.6.2017

Timo Turkkila

Dtream Oy (www.dtream.fi)

Soukanlahdenkatu 17 A

33100 Tampere

timo.turkkila@dtream.fi 